\title{
CALCIFICATION OF THE AORTIC VALVE AND OF THE CORONARY ARTERIES
}

\author{
BY \\ DAVID PYKE AND CECIL SYMONS \\ From the Royal Northern Hospital, London \\ Received February 26, 1951
}

This paper reports a clinical and radiological survey to find the frequency of calcareous aortic stenosis and of calcification elsewhere in the heart. 400 men over the age of 60 were chosen at random-200 in- or out-patients of a general hospital (series A) and 200 in-patients of a mental hospital (series B). In the clinical examination Levine's (1945) method of grading the loudness of murmurs was used. The technique of X-ray screening was that described by Sosman (1943). To compare the clinical and post-mortem incidence of cardiac calcification, 72 hearts from consecutive routine necropsies were radiographed.

\section{RESULTS}

Among the 400 men, 27 cases $(6.75 \%)$ of cardiac calcification were detected on screening: aortic valve (Fig. 1), 11 cases $(2.75 \%)$; coronary arteries (Fig. 2, 3 and 4$), 14$ cases (3.5\%); mitral valve (Fig. 5), 1 case; pericardium, 1 case.

Calcified aortic valve. The clinical findings in these 11 cases are set out in Table I, and their average age, compared with other patients', in Table II. There was no past history of rheumatic fever. Six of the seven men in series A had been passed fit for military service in 1914-18 and three had served throughout that war. Three of the four men in series B, being examined annually, were noted, after being found free of murmurs for 12, 31 and 37 years, to have developed systolic murmurs at the ages of 65,54 and 66 respectively. In only three patients was dyspnœa a feature; one patient had a history of six months' angina of effort.

The physical signs were those generally found in aortic stenosis. The second heart sound at the base was diminished or absent in all cases except one. A systolic murmur was present in all and a diastolic in one; there was a systolic thrill in five patients. However, none had a plateau pulse and, in all except one, the pulse pressure was normal. Electrocardiograms were taken in six cases. Three showed left ventricular preponderance, one auricular fibrillation with incomplete right bundle branch block, one left axis deviation, and one was normal.

On screening, the left ventricle was enlarged in 7 cases. Calcification, when present, was always seen in the right anterior oblique position (Fig. 1.) but in the left anterior oblique in only seven cases. There was no clinical or radiological evidence of mitral stenosis in any case.

Two patients have died, both of them suddenly.

Calcified coronary arteries were detected, by screening, in 14 cases (Fig. 2, 3, and 4). They were significantly older than the patients without coronary calcification (see Table' II). The clinical histories showed nothing significant except for a patient with effort dyspnœa whose blood pressure was 270/160. There was hypertension in four patients (diastolic over 100). There was a systolic murmur in seven, of whom three were hypertensive.

Calcification was seen in the left coronary artery in 10 cases (circumflex 9 , descending 1 ), in the 355 


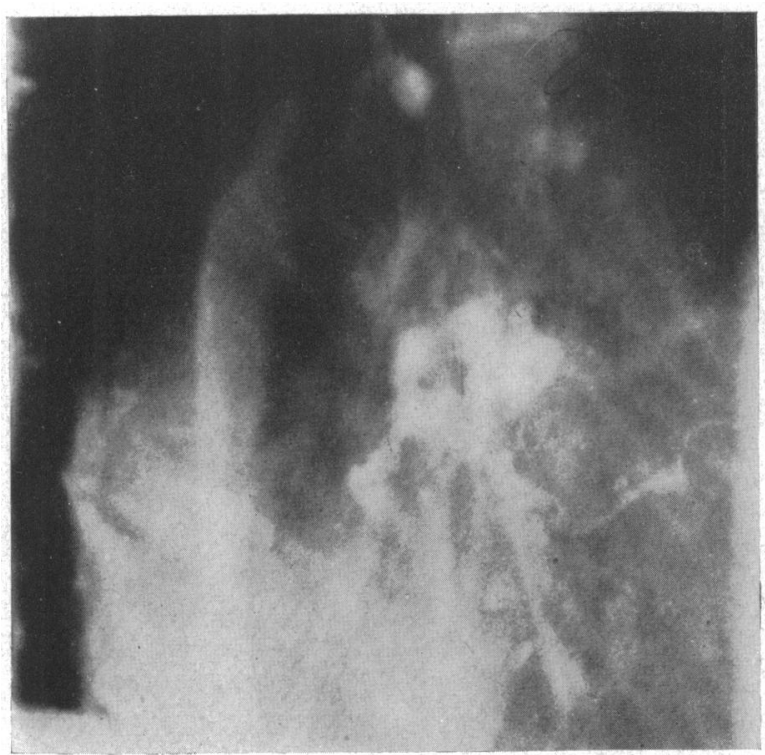

Fig. 1.-Calcified aortic valve-R.A.O. view.

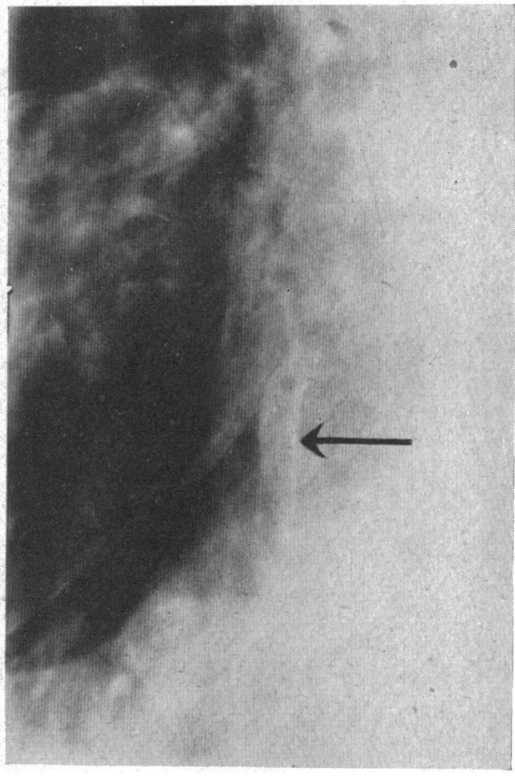

FIG. 2.-Calcified right coronary artery. Patient slightly rotated to his right, i.e. a $5^{\circ}$ left anterior oblique view.

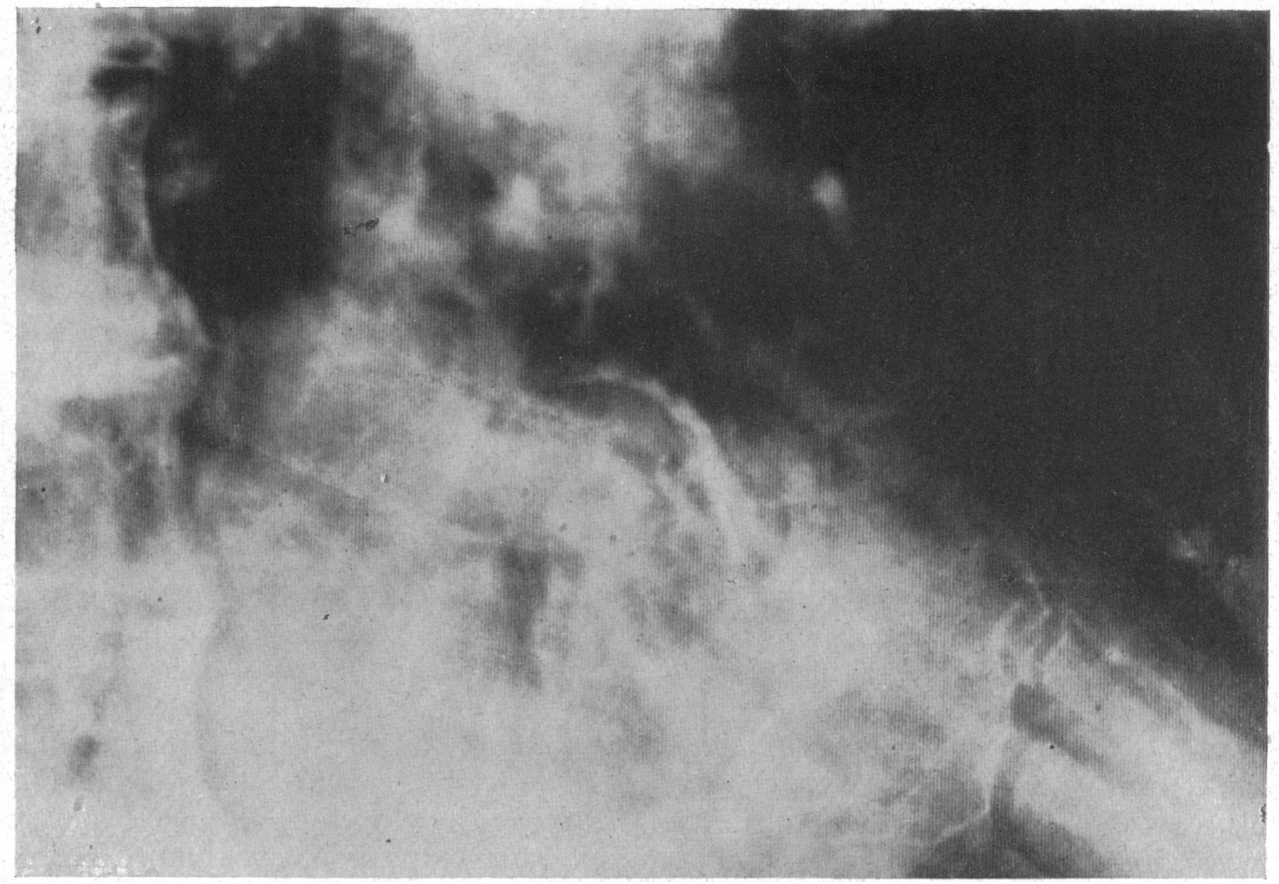

FIG. 3.-Calcified left coronary artery (descending branch). In this view (R.A.O.) the positions of the descending and circumflex branches are similar. 


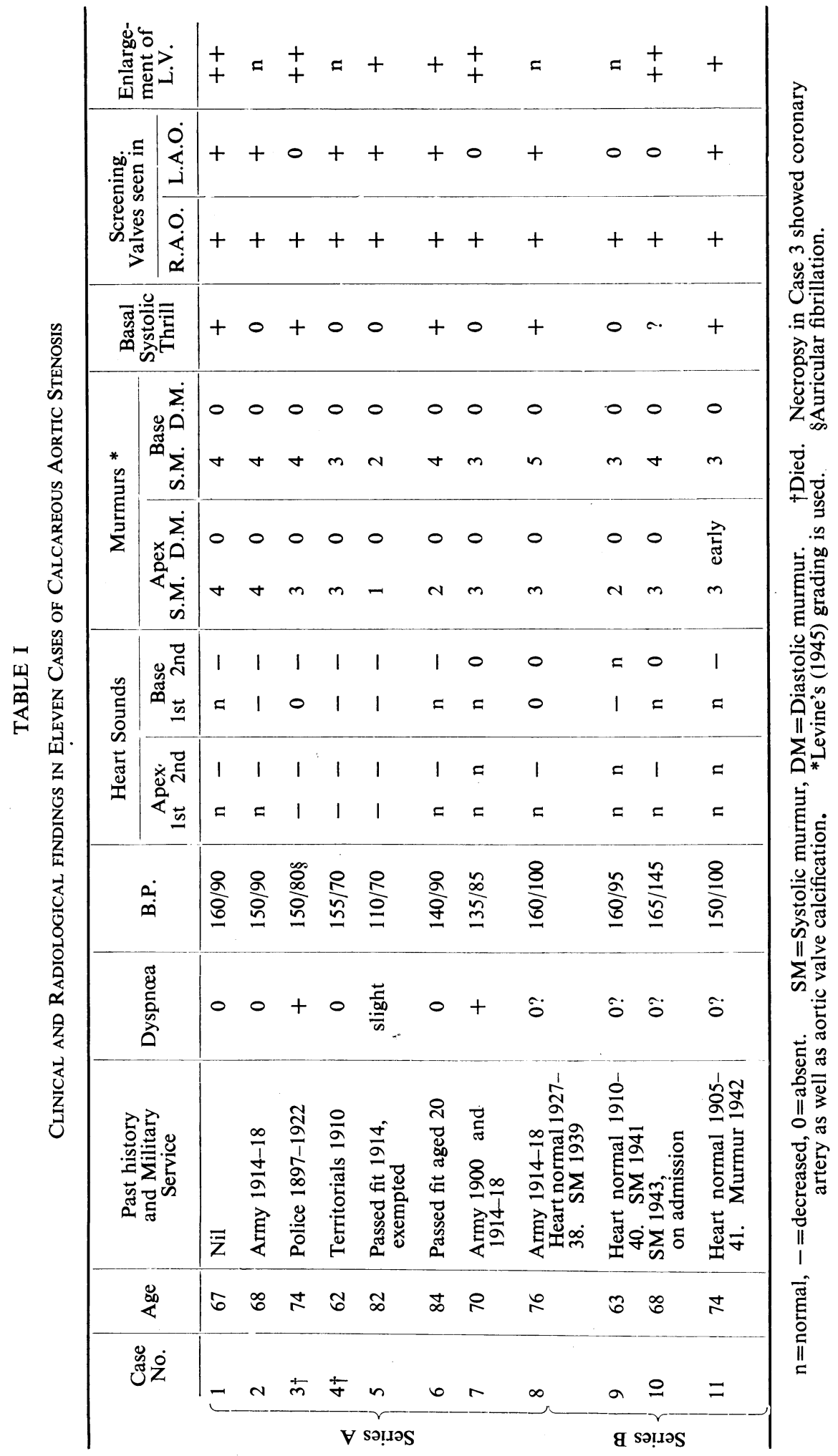



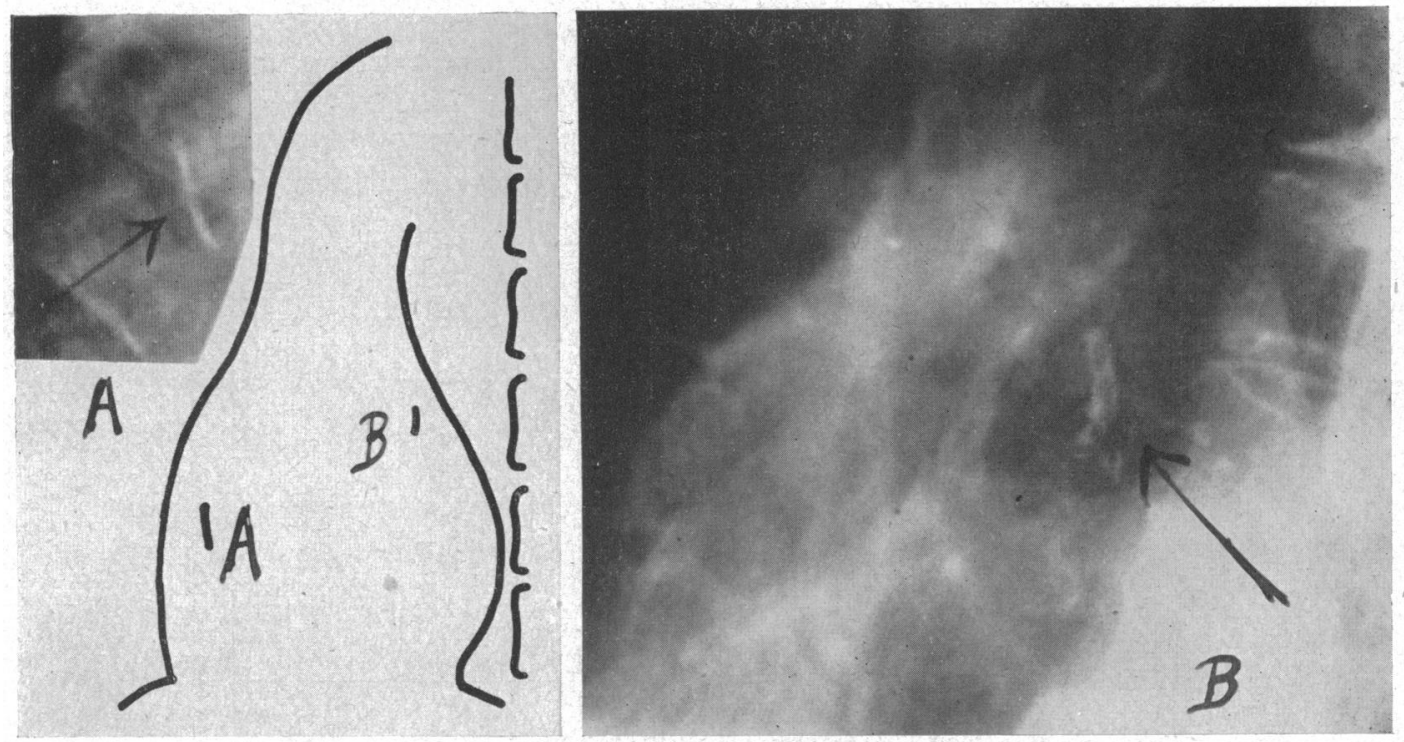

Fig. 4.-Calcified left coronary artery. Two pictures illustrate the distinction between the descending and the circumflex branches in the left anterior oblique view. The descending branch is seen near the anterior border of the heart (A) and the circumflex branch near the posterior border (B).

right coronary in 3 , and in the right and circumflex branch of the left in one case. There was no cardiac enlargement except in the presence of hypertension.

Electrocardiograms were taken in three of the four cases in series. A. One showed left ventricular preponderance and the other two were normal. The Wassermann reaction was done in eight cases and was negative.

Calcification of the mitral valve was detected in one man and was confirmed at necropsy. Calcification of the pericardium was found in one man who gave no past history of rheumatic or tuberculous disease and who had neither symptoms nor signs of heart disease.

No case of calcification confined to the annulus fibrosus nor of the myocardium was observed.

\section{Radiography OF THE IsOlated Heart Post MORTEM}

72 hearts of patients of all ages (of whom 50 were over 60 ) from consecutive routine necropsies were radiographed. In this way small areas of calcification can be seen-areas that are too slight to be detected by X-ray screening during life or even by naked-eye examination at necropsy. Figures based on post-mortem radiography showed an incidence of calcification in the aortic valve in patients over the age of sixty of 44 per cent ( 22 out of 50 ), whereas in a series of 563 necropsies

TABLE II

Average Age of Different Groups

\begin{tabular}{ll|c|c|c|c|c|c}
\hline & \multicolumn{2}{|c|}{ Series A } & \multicolumn{2}{c|}{ Series B } & \multicolumn{2}{c}{ All cases } \\
\cline { 3 - 7 } & & Number & Age & Number & Age & Number & Age \\
\hline With calcified aortic valves & $\ldots$ & 7 & $72 \cdot 4$ & 4 & $70 \cdot 3$ & 11 & $71 \cdot 6$ \\
With calcified coronary arteries & $\ldots$ & 4 & 72 & 10 & 74 & 14 & $73 \cdot 4$ \\
Without cardiac calcification &. & $187^{*}$ & $68 \cdot 1$ & 186 & $68 \cdot 4$ & $373^{*}$ & $68 \cdot 3$ \\
\hline
\end{tabular}

* Excluding one case of pericardial and one of mitral valve calcification. 


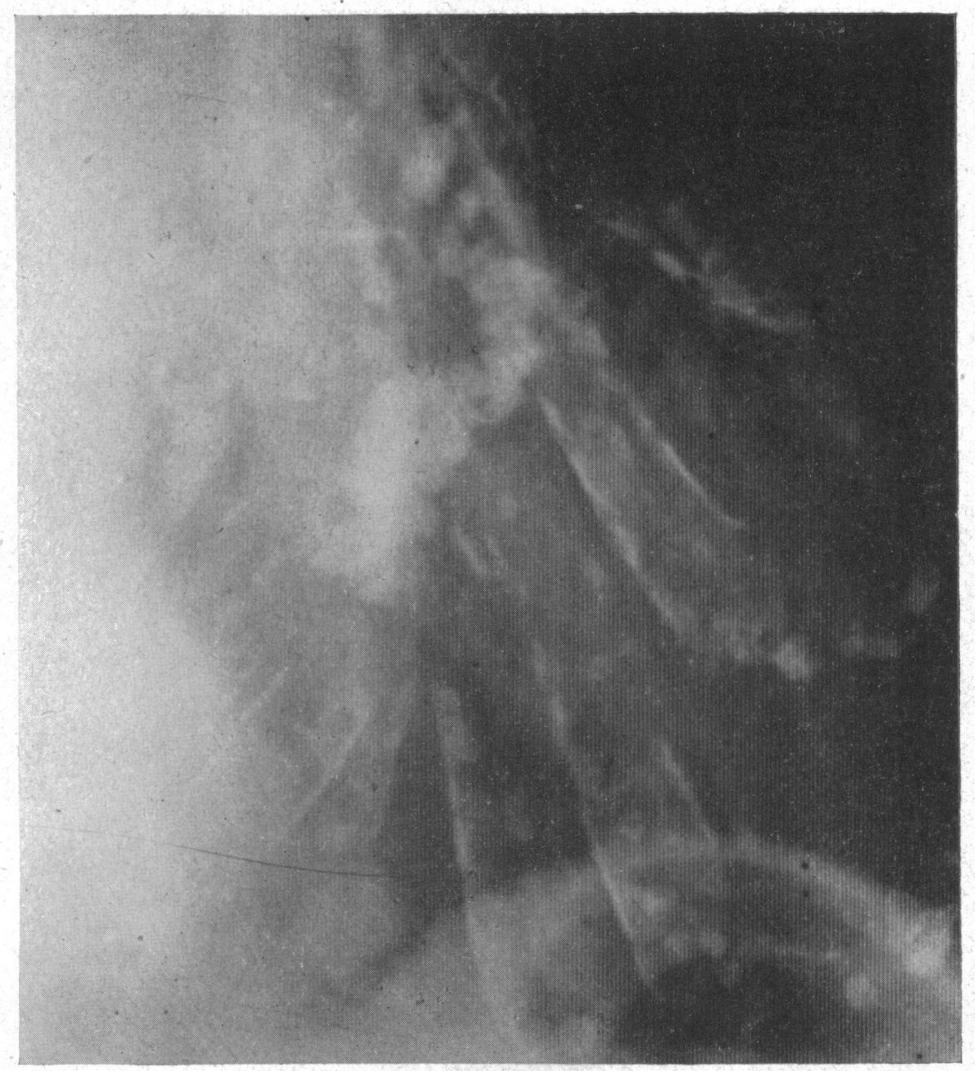

FIG. 5.-Calcification of the mitral valve. Right anterior oblique position. The appearance is distinct from that of the aortic valve (Fig. 1), the calcification being compact and nodular in the-mitral, but fragmented and irregular in the aortic valve.

naked-eye examination gave a figure of only 5.5 per cent for the same age group. This suggests that post-mortem radiography reveals calcification eight times as often as naked-eye examination.

The findings in the 72 hearts are set out in Table III. In 22 hearts $(30 \%)$ there was calcification of the aortic valve. Usually this consisted of one or two small flecks of calcium along the line of attachment of the valve cusps, but it often extended into the leaflet and in three cases was only present in the leaflet (Fig. 6). The calcification tended to spread inwards from points on the ring

TABLE III

Radiography of The Heart Post Mortem

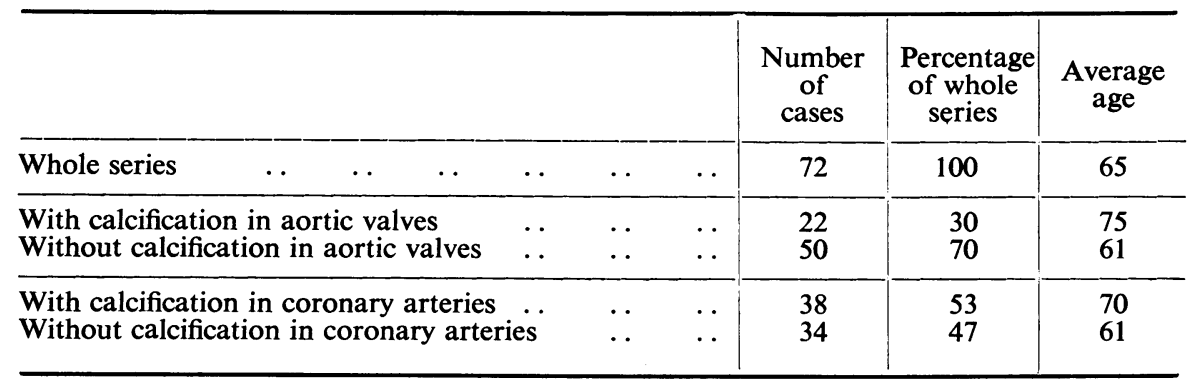


at 4 o'clock and 8 o'clock. In no case was there any narrowing of the valve orifice. All but four of the cases also showed coronary artery calcification.

Four of the 22 cases had been noted to have systolic murmurs. In sixteen no murmurs had been recorded and in two there were no notes. All 22 were over 60 and their average age was 14 years more than that of the remainder.

Calcification of the coronary arteries was present in 38 cases $(53 \%)$ and was commoner in the left than in the right. Those with coronary artery calcification were, on the average, nine years older than those without it. Sixteen of eighteen patients over the age of 75 had calcification of the coronary arteries and 14 also of the aortic valve.

Mitral valve calcification was present in the hearts of four women, but in only one was there . stenosis. Two of the others were noted to have had systolic murmurs; the findings in the third were not recorded.

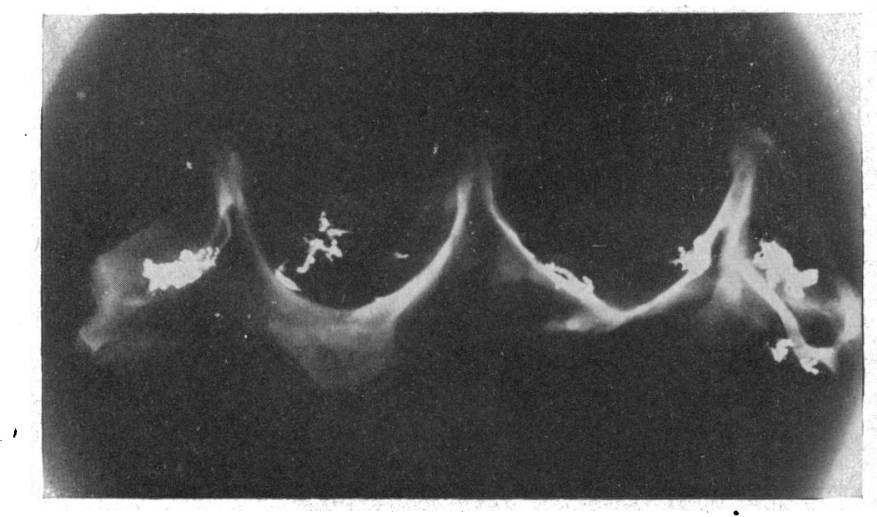

FIG. 6.-Typical calcification in the aortic valve of a man aged 81 . The calcium is situated along the line of attachment of the cusps and in the leaflets. This man, who had not been screened in life, presented no sign of heart disease.

FIG. 7.-The aortic valve of a man aged 72 with Lutembacher's syndrome. When he was screened during life no calcium was detected. Presumably, more calcium than this must be deposited before it can be seen on the X-ray screen.

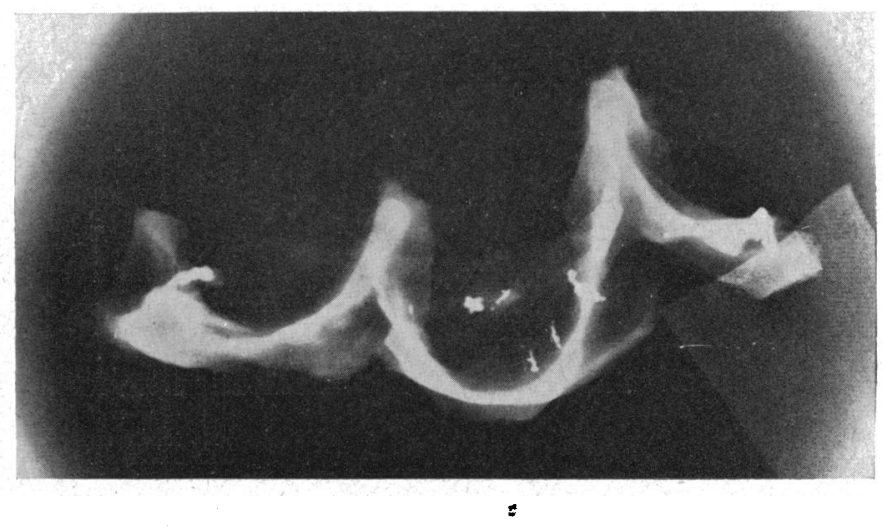

Discussion

Cardiac calcification is more easily detected by fluoroscopic screening than by radiography. When taking radiographs, as when screening, it is best to use a small aperture.

Calcareous aortic stenosis. McGinn and White (1934) found aortic stenosis in 2.3 per cent of 4800 cardiac patients, but do not separate those with calcification. Habbe and Wright (1950) detected valvular calcification in approximately 1.5 per cent of 1000 patients over the age of 40 . "referred for cardiac roentgen study," but they do not state how many were aortic. The incidence of calcareous aortic stenosis at necropsy was found by Friedewald and Ewing (1938) to be 0.3 per cent, and by McGinn and White (1934) to be 1.8 per cent. 
The clinical picture of aortic stenosis in these eleven cases conforms to that described by McGinn and White (1934) and by Contratto and Levine (1937). Only three presented with breathlessness or pain on effort and the others would presumably not have been diagnosed as suffering from aortic stenosis unless they developed symptoms of heart trouble.

Since only half the patients had thrills and only one had a reduced pulse pressure, the diagnosis was not always certain before screening. The presence of calcification in the aortic valve establishes the diagnosis of aortic stenosis (Wood, 1948). Whether aortic stenosis ever occurs in this age group without calcification is doubtful. There is no recent report of aortic stenosis in a patient of 60 without calcification also being noted (Davies and Steiner, 1949; McGinn and White, 1934; Contratto and Levine, 1937; Gibbs, 1935; Dry and Willius, 1939; Kumpe and Bean, 1948; and Lewes, 1951): however, not all the patients described by these authors were screened during life, the calcification being discovered at necropsy; nor were all their ages recorded.

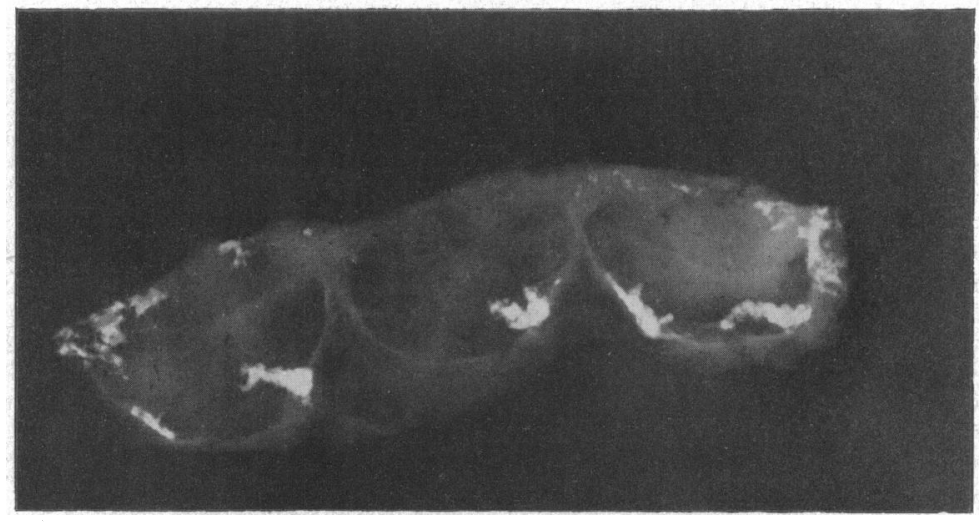

Fig. 8.-Calcareous aortic stenosis (Case 4). Calcification of the valve was seen on fluoroscopic screening during life.

Previous reports on necropsy material mention the infrequency with which a correct diagnosis has been made during life (a third in the series of McGinn and White's (1934) and a half in that of Thompson and Levine's (1936)). If the presence of a persistent systolic murmur in an elderly person is taken as an indication for screening, the diagnosis of aortic stenosis should be made with a high degree of accuracy.

The amount of calcium that must be present in the aortic valve to be visible on the screen presumably varies with the build of each patient. But Fig. 7 shows the aortic valve of a man of 72 , not in this series, who had Lutembacher's syndrome. Screening during life did not reveal the valvular calcification. Calcification in Case 4, on the other hand, had been easily detected on screening and at necropsy was found to be extensive (Fig. 8). The amount of calcium that must be present to be visible on screening in life may lie between these two extremes.

There are two opposing views on the ætiology of calcareous aortic stenosis. Karsner and Koletsky (1947) have summarized the evidence in support of a rheumatic basis and in their own series of 200 necropsy cases they found histological evidence of past rheumatic infection of the heart in 98 per cent. The theory that the condition may often be atheromatous, originally put forward by Monckeberg in 1904, is supported by pathologists who have not found such frequent histological evidence of past rheumatism (Sohval and Gross, 1936; Friedewald and Ewing, 1938; and Hultgren, 1948). The rheumatic theory is the more widely accepted by clinicians (Parkinson, 1949; Dry and Willius, 1939; McGinn and White, 1934; Contratto and Levine, 1937). There does not seem, however, to be agreement on the definition of histological evidence of past rheumatic infection of 
the heart. The figures for the incidence of such evidence in unselected material vary from 11 per cent (Hultgren, 1948) to 93 per cent (Hall and Anderson, 1943).

Three of the four patients in series B with aortic stenosis were known not to have developed murmurs until the ages of 65,54 , and 66 . This late development of the murmur suggests that, if these patients had had rheumatic fever, there had either been an exceptionally long interval between it and the development of the murmur or the rheumatism had occurred later in life than is usual.

The average age of the eleven cases of aortic stenosis was higher than the average for the rest (excluding other cases of cardiac calcification) but the difference was not statistically significant $(\mathrm{t}=1.689, P=0.092)$. Sophian's (1945) series also shows an age difference: he reported 31 cases of calcareous aortic valvular stenosis from 500 necropsies, whose average age was 49 , and divided them into 17 rheumatic and 14 non-rheumatic, chiefly on the basis of involvement of the mitral valve. From his figures one can calculate that the average age of the rheumatic group was 46; of the non-rheumatic group it was 60 . In Ashworth's (1946) series of 500 necropsies, the patients with calcareous aortic stenosis were considerably older than the rest. It seems unlikely that any group of patients with rheumatic heart disease lives for longer than normal people.

Hultgren (1948) radiographed 100 hearts from routine necropsies and found calcium in the aortic valve in 46. Windholz and Grayson (1947) quote 8 per cent as the necropsy incidence of valvular calcifications. In this series aortic valve calcification was found in 22 hearts out of 72 . The fact that these patients are older than the rest suggests that the calcification of the aortic valve, as detected by post-mortem radiography, is a degenerative condition. The pattern of valve calcification appeared to be similar in the 22 shown at necropsy and in the 2 diagnosed in life as suffering from calcareous aortic stenosis (Fig. 6 and 8). The pattern of calcification in the aortic valve, where it is fragmented and irregular, is distinct from that in the mitral where the calcium is compact and nodular (Cf. Fig. 1 and 5).

Coronary artery calcification. This was found by Habbe and Wright (1950) in approximately 3 per cent of their 1000 patients over 40 years of age. Sosman in 1943 reported coronary artery calcification in 42 of 204 cases of cardiac calcification that he had then seen.

When a calcified left coronary artery is seen on the screen it may be impossible to distinguish between the descending and the circumflex branches in the first oblique view, but in the second oblique the circumflex is seen near the posterior border of the heart and the descending near the anterior border (Fig. 3 and 4). The movement of the coronary arteries is usually marked, especially near their origin from the aorta. Coronary vessels may be distinguished from aortic valves, not only by their position and movement, but because they are usually linear and nearly homogenous shadows, whereas calcified aortic valves appear irregular and granular (Fig. 1). Since post-mortem radiography shows that about half of all hearts show coronary artery calcification it is clear that only a fraction of these cases are diagnosed in life.

Patients in this series with coronary artery calcification did not show clinical evidence of impaired coronary function.

\section{SUMMARY AND CONCLUSIONS}

400 men over the age of sixty were examined clinically and radiologically in order to determine the incidence of cardiac calcification.

Calcification of the aortic valve was found in eleven $(2.75 \%)$ and of the coronary arteries in fourteen $(3 \cdot 5 \%)$.

The patients with calcification of the aortic valve presented the signs of aortic stenosis. Their average age was slightly greater than that of the patients without calcification. Three men with calcareous aortic stenosis were known not to have developed murmurs until the ages of 65,54 , and 66.

Radiography of the isolated heart post-mortem showed calcium in the aortic valve in 22 of 
72 cases. These patients were 14 'years older, on an average, than those without aortic valve calcification. It is suggested that calcareous aortic stenosis may be a degenerative disease.

Coronary artery calcification was not associated with evidence of impaired coronary function. By post-mortem radiography it was found to occur in 38 of the 72 cases. Patients with coronary artery calcification were, on an average, older than those without it.

We wish to thank Sir John Parkinson for his advice and criticism, Professor J. McMichael for reading the manuscript and Mr. N. W. Please for statistical help. We are most grateful to Sister Hathway, Miss Violet Pilton and the other radiographers at the Royal Northern Hospital for their co-operation. We are also indebted to the consultant staff of the Royal Northern Hospital for access to their patients and to Dr. B. B. Zeitlyn for enabling us to examine the patients in the mental hospital.

\section{REFERENCES}

Ashworth, C. T. (1946). Arch. Path., 42, 285.

Contratto, A. W., and Levine, S. A. (1937). Ann. intern. Med., 16, 1636.

Davies, C. E., and Steiner, R. E. (1949). Brit. Heart J., 11, 126.

Dry, T. J., and Willius, F. A. (1939). Amer. Heart J., 17, 138.

Friedewald, W. F., and Ewing, A. R. (1938). Amer. J. med. Sci., 196, 400.

Gibbs, A. J. (1935). Guy's Hosp. Rep., 85, 275.

Habbe, J. E., and Wright, H. H. (1950). Amer. J. Roentgen., 63, 50.

Hall, E. M., and Anderson, L. R. (1943). Amer. Heart J., 25, 64.

Hultgren, H. N. (1948). Arch. Path., 45, 694.

Karsner, H. T., and Koletsky, S. (1947). Calcific Disease of the Aortic Valve, Philadelphia.

Kumpe, C. W., and Bean, W. B. (1948). Medicine, 27, 139.

Levine, S. A. (1945). Clinical Heart Disease, Philadelphia.

Lewes, D. S. (1951). Brit. med. J., 1, 211.

McGinn, S., and White, P. D. (1934). Amer. J. med. Sci., 188, 1.

Monckeberg, J. G. (1904). Virchows Arch., 146, 472.

Parkinson, J. (1949). Lancet, 1, 895.

Sohval, A. R., and Gross, L. (1936). Arch. Path., 22, 477.

Sophian, L. H. (1945). Amer. J. med. Sci., 210, 644.

Sosman, M. C. (1943). Amer. J. Roentgen., 50, 461.

Thompson, W. P., and Levine, S. A. (1936). New. Engl. J. Med., 215, 670.

Windholz, F., and Grayson, C. (1947). Amer. J. Roentgen., 58, 411.

Wood, P. (1948). In Modern Trends in Diagnostic Radiology (Ed. McLaren), London. 